\title{
Forum
}

\section{Schwerpunkt: Renaissance der Ideologie?}

Als Francis Fukuyama 1992 in seinem berühmten Werk das „Ende der Geschichte“ verkündete, postulierte er zugleich das Ende des Kampfes der Ideologien - zumindest in der Weise, wie er einen Großteil des 20. Jahrhunderts maßgeblich geprägt hatte. Mit dem Ende des Ost-West-Konfliktes hatte sich die liberale Demokratie endgültig gegen totalitäre Ideologien und Systeme durchgesetzt und ihre Überlegenheit bewiesen. Die Menschheit würde in eine neue, friedliche Entwicklungsphase eintreten, Ideologien an Bedeutung verlieren - so die Vermutung.

Wird heute in politischen Auseinandersetzungen der Ausdruck „Ideologie“ gebraucht, werden politische Positionen als ,ideologisch“ bezeichnet, dient dies in erster Linie der De-Legitimierung des politischen Gegners. Diesem fehle aufgrund doktrinärer Verblendung die Einsicht in die - häufig mit wissenschaftlichen Begründungen unterfütterten - „objektiv“ gebotenen Erfordernisse politischen Handelns; mitunter soll ihm schlicht der gesunde Menschenverstand abgesprochen werden. In der Bundesrepublik lässt sich seit einigen Jahren eine Politik beobachten, die sich selbst als ideologiefrei begreift, sich dagegen als pragmatisch, an den „Anforderungen des Tages“" ausgerichtet, zweckrational, geradezu als ,alternativlos“ versteht.

Schaut man dieser Tage hingegen über Deutschland hinaus und blickt zum Konflikt zwischen Russland und der Ukraine, dann erinnert dieser an militärische Muskelspiele und Machtpolitik, wie sie für das ideologisch geprägte späte 19. und 20. Jahrhundert typisch waren. Auch im asiatisch-pazifischen Raum bahnt sich mit dem rasanten Aufstieg Chinas eine Auseinandersetzung zwischen der Volksrepublik und den USA an, die Züge der Systemkonfrontation des 20. Jahrhunderts trägt.

Vor diesem Hintergrund beschäftigt sich das folgende Forum mit der Frage, ob wir gegenwärtig Zeuge einer Renaissance der Ideologie in der Politik werden. Oliver W. Lembcke beleuchtet hierfür aus der Sicht der Politischen Ideengeschichte, Philosophie und Theorie den Stellenwert von Ideologien in der Politik. Danny Michelsen und Franz Walter beschäftigen sich aus der Perspektive der politischen Systemforschung insbesondere mit der Ideologie des Populismus und ihrer Wirkung auf die Demokratie. Carlo Masala unterstreicht abschließend die ungebrochene Bedeutung realistischer Theorien für das Verständnis internationaler Politik. 